\title{
Split Sternotomy in Retrosternal Thyroid and Mediastinal Parathyroid Pathologies
}

\author{
Selda Gucek Haciyanli, ' (i) Serkan Karaisli,' (i) Nihan Acar, ${ }^{1}$ (i) Bortecin Eygi, ${ }^{2}$ (i) Mehmet Haciyanli' \\ 'Department of General Surgery, Izmir Katip Celebi University Ataturk Training and Research Hospital, Izmir, Turkey \\ ${ }^{2}$ Department of Cardiovascular Surgery, Izmir Katip Celebi University Ataturk Training and Research Hospital, Izmir, Turkey
}

\begin{abstract}
Objectives: Although cervical incisions are usually sufficient in mediastinal located thyroid and parathyroid pathologies, sometimes mediastinal approaches are required. In recent years, less invasive methods have been used instead of median sternotomy. In this study, the adequacy of the incision and morbidity in patients who underwent split sternotomy due to retrosternal goiter (RG) and mediastinal parathyroid pathology in our clinic were investigated.

Methods: The files of patients who underwent split sternotomy in addition to cervical incision or split sternotomy extending from the sternal notch to the third intercostal space with a separate vertical incision due to retrosternal thyroid pathology or mediastinal ectopic parathyroid adenoma between January 2010 and January 2021 were retrospectively reviewed. Operative success, exposure provided by split sternotomy, and complication rates were investigated.

Results: Twelve patients who underwent split sternotomy were included in the study. The mean age of the patients was $57.25 \pm 12.62$ (44-83) years. Eight $(66.7 \%)$ of the patients were female and $4(33.3 \%)$ were male. The indication for surgery was multinodular goiter (MNG) in $3(25 \%)$ patients, recurrent MNG in $3(25 \%)$ patients, hyperparathyroidism in $3(25 \%)$ patients, and thyroid cancer in $3(25 \%)$ patients. Transient hypocalcemia in $6(50 \%)$ patients and unilateral vocal cord paralysis in $1(8.3 \%)$ patient developed postoperatively, and all complications resolved spontaneously in an average of 3 weeks. Median sternotomy was not required for any of the patients.

Conclusion: Split sternotomy is an adequate and applicable method for the success of the surgery in RG and mediastinal parathyroid pathologies that cannot be excised with the cervical approach.

Keywords: Mediastinal parathyroid; retrosternal goiter, split sternotomy.

Please cite this article as: Gucek Haciyanli S, Karaisli S, Acar N, Eygi B, Haciyanli M. Split Sternotomy in Retrosternal Thyroid and Mediastinal Parathyroid Pathologies. Med Bull Sisli Etfal Hosp 2021;55(3):318-324.
\end{abstract}

\section{Introduction}

Thyroid and parathyroid glands are the endocrine glands that are expected to be anatomically located in the neck. However, the extension of the severely enlarged thyroid gland to the mediastinum or its localization in the mediastinum can be seen due to the problems of the parathyroid glands in the embryological development process. The definition of retrosternal goiter (RG) is used for an enlarged thyroid gland with mediastinal extension; it is mostly used synonymously with intrathoracic goiter and substernal goiter. ${ }^{[1]}$ It has been observed that in $1-20 \%$ of the patients presenting with thyroid disease,

Address for correspondence: Selda Gucek Haciyanli, MD. Basin Sitesi mah. Hasan Tahsin Caddesi, Karabaglar, Izmir, Turkey

Phone: +90232 2444444 E-mail: msgucek@hotmail.com

Submitted Date: May 12, 2021 Accepted Date: June 02, 2021 Available Online Date: September 24, 2021

${ }^{\circ}$ Copyright 2021 by The Medical Bulletin of Sisli Etfal Hospital - Available online at www.sislietfaltip.org

OPEN ACCESS This is an open access article under the CC BY-NC license (http://creativecommons.org/licenses/by-nc/4.0/). 
the thyroid gland is located retrosternal. Its incidence is higher in patients over the age of 50, and it is observed 4 times more frequently in women than in men. ${ }^{[2]}$ The most common cause of complaints in symptomatic patients is compression on the trachea and esophagus. Dysphagia and dyspnea, which are usually aggravated when lying on the back, are the main symptoms. In advanced cases, superior vena cava syndrome may occur due to venous vascular compression. It is accepted that it should be treated because of its possible malignancy risk and rapid growth. ${ }^{[1,3]}$

Thyroidectomy can be performed with a standard cervical incision in more than $90 \%$ of RG cases extending to the anterior mediastinum. ${ }^{[4]}$ However, mediastinal approaches may be required in cases of large-sized goiter and cases with advanced mediastinal extension. Ectopic parathyroid glands are usually found in thymic tissue in the anterior-upper mediastinum. The pathological ectopic gland can be excised with the cervical approach in most cases. However, in approximately $1-2 \%$ of the patients, a mediastinal approach may be required because the mediastinal parathyroid tissue cannot be reached with a standard cervical incision. ${ }^{[5]}$

Since the median sternotomy causes complications such as deep surgical site infections, sternal dehiscence, arrhythmias, sternal instability, and internal mammary vessel injuries, and less common invasive methods such as split sternotomy (incision starting from the sternal notch to the third intercostal space) ${ }^{[6]}$ a video-assisted thoracoscopic surgery (VATS) has been developed. ${ }^{[1]}$

In this study, we aimed to evaluate the adequacy and morbidity of split sternotomy applied in our clinic for retrosternal thyroid and mediastinal parathyroid pathologies.

\section{Methods}

The files of 246 consecutive patients who were operated on due to retrosternal thyroid pathology or mediastinal ectopic parathyroid adenoma in the Izmir Katip Celebi University between January 2010 and January 2021 were analyzed retrospectively. Patients who underwent split sternotomy were included in the study. Patients who underwent total sternotomy and those with missing file information were excluded from the study. Patients' demographic characteristics, surgical indications, pathologic examination results, and surgical complications were recorded based on patient files and database information. All cases with goiter/thyroid cancer extending $10 \mathrm{~cm}$ inferior to the jugular notch (Fig. 1) and ectopic mediastinal parathyroid adenoma in the neck computed tomography (CT) findings were evaluated preoperatively in terms of split sternotomy and their written informed consents were obtained. As a standard approach, first, a cervical incision was performed. Split sternotomy was applied in two ways in patients whose mediastinal thyroid or parathyroid tissue could not be reached by a cervical incision. Pathological thyroid or parathyroid tissue was reached by making either a " $\mathrm{T}$ " incision which cervical incision is on

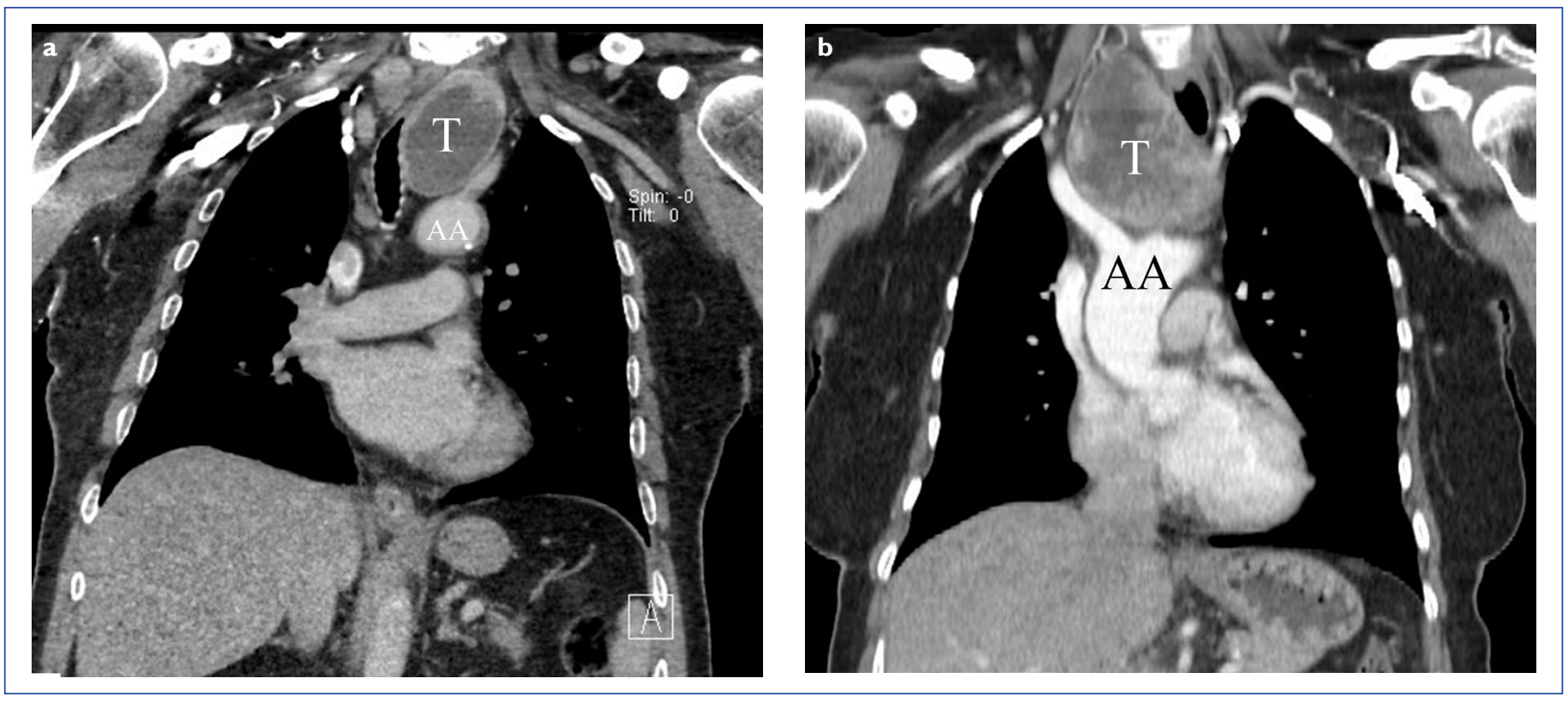

Figure 1. $(a, b)$ Computed tomography images of retrosternal goiter patients. Thyroid tissueis observed to extend to the aortic arch in both patients and the trachea deviates to the contralateral side. 


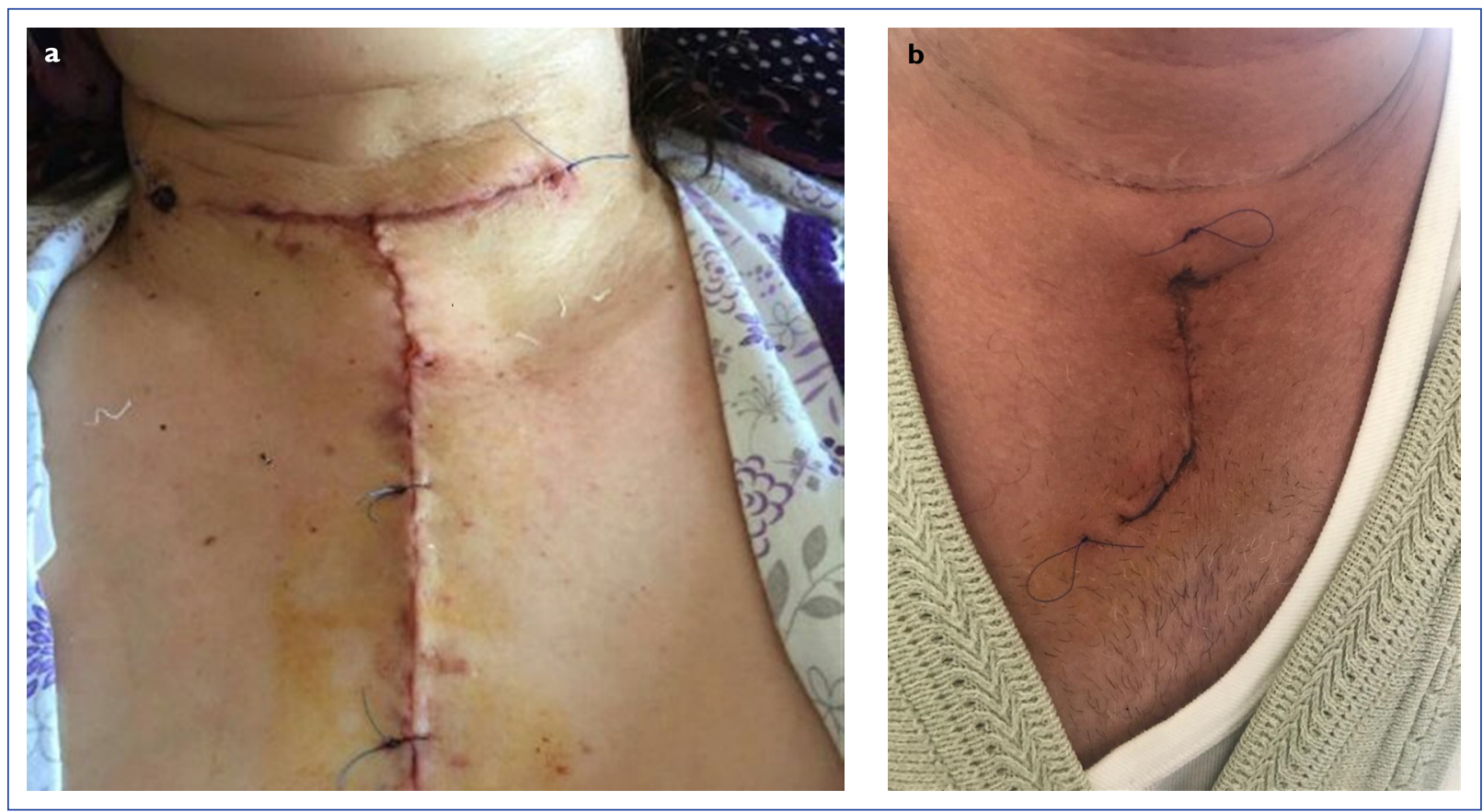

Figure 2. " $T$ " incision in which cervical incision and sternotomy are combined (a) and vertical incision extending from the sternal notch to the third intercostal space (b).

the superior border (Fig. 2a) or a separate $5 \mathrm{~cm}$ vertical upper mini-J incision (Fig. 2b) extending from the sternal notch to the third intercostal space without reaching to the internal mammary vessels. Intraoperative neuromonitorization for recurrent laryngeal nerves was performed in all thyroid cases. Operative success, exposure provided by split sternotomy, and complication rates were examined.

Ethics committee approval for this study was obtained from İzmir Katip Çelebi University Ethics Committee (decision number 1122, dated 24.12.2020). Written informed consents were obtained from the patients/patient relatives who participated in this study.

\section{Statistical Analysis}

Statistical analyzes were performed using the Statistical Package for the Social Sciences version 20.0 (IBM Corp.; Armonk, NY, USA). Mean \pm standard deviation and percentage and frequency values were used for variables.

\section{Results}

Twelve $(12 / 246=4.9 \%)$ patients who underwent split sternotomy due to retrosternal thyroid pathology or mediastinal ectopic parathyroid adenoma were included in the study. One patient who underwent total sternotomy was excluded from the study. The mean age of the patients was calculated as $57.25 \pm 12.62$ (44-83) years. Eight (66.7\%) patients were female and four $(33.3 \%)$ were male. The

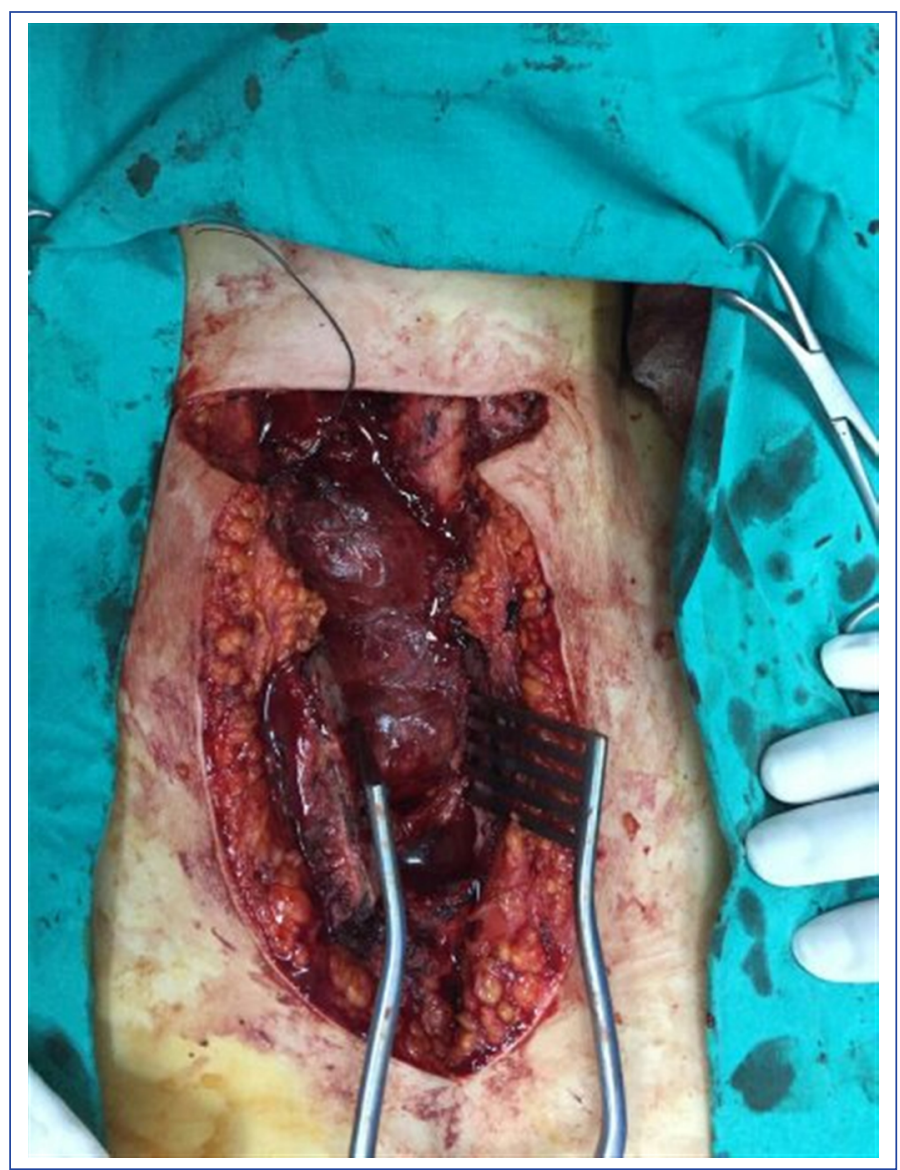

Figure 3. Surgical view of a retrosternal goiter patient who underwent split sternotomy. 


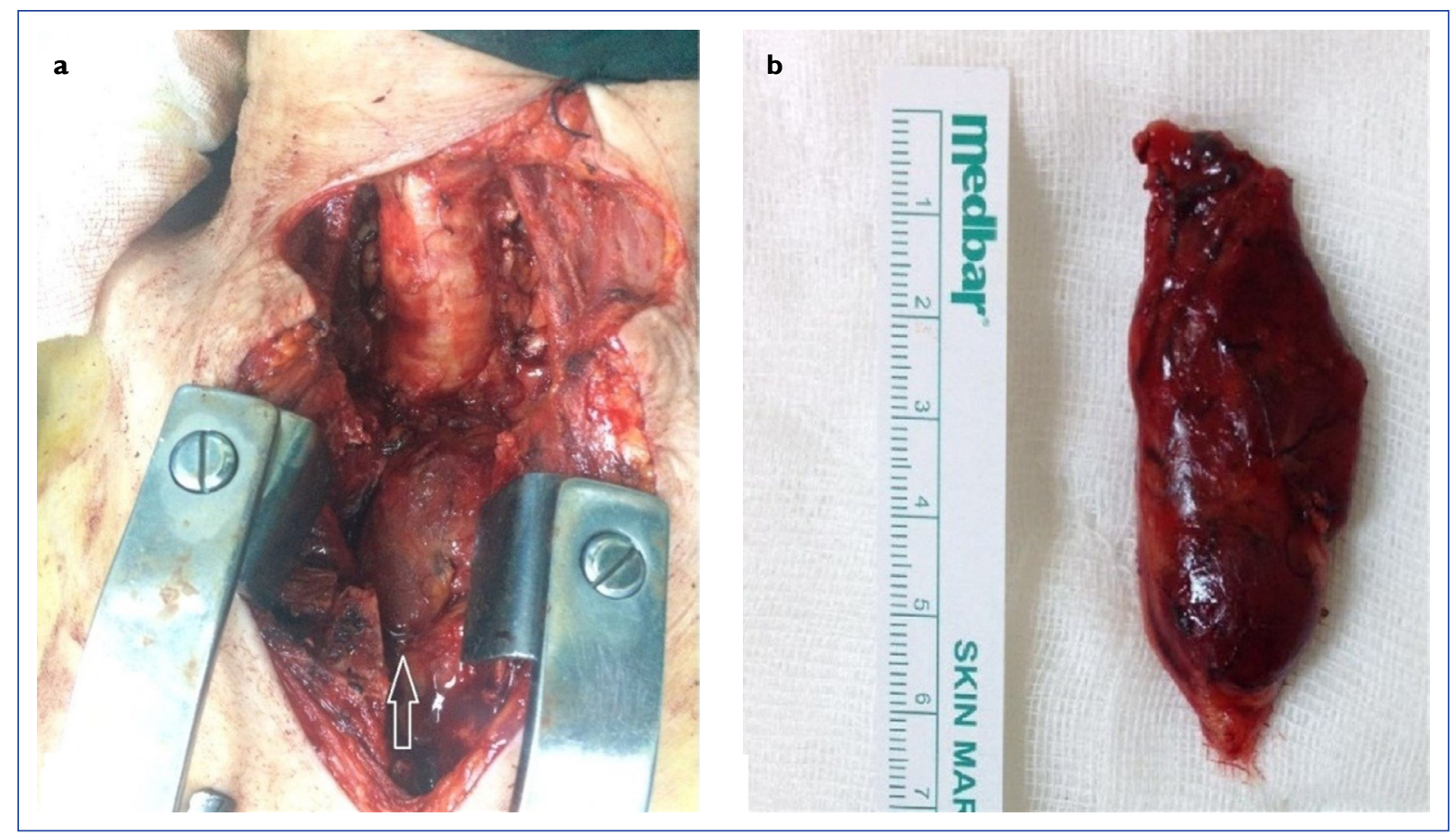

Figure 4. Surgical view (a) and macroscopic view (b) of the giant parathyroid adenoma (arrow) in a patient who underwent split sternotomy.

indication for surgery was multinodular goiter (MNG) in $3(25 \%)$ patients, recurrent MNG in $3(25 \%)$ patients, primary hyperparathyroidism (HPT) in $2(16.7 \%)$ patients, secondary HPT in $1(8.3 \%)$, and thyroid cancer in $3(25 \%)$ patients. (Figures 3 and 4). While one of the thyroid cancer cases was anaplastic thyroid cancer, papillary cancer was diagnosed in the others. Seven patients (58.3\%) had signs of compression causing dyspnea. The procedure is the first intervention in $6(50 \%)$ of the patients and $6(50 \%)$ patients had a history of previous cervical intervention. The mean operation time was calculated as $227.7 \pm 36.3 \mathrm{~min}(163-$ 285). It was possible to reach all pathological thyroid and parathyroid tissues through the split sternotomy incision, to perform their dissection, to clearly reveal the recurrent laryngeal nerves and major vascular structures (innominate vein, aortic aorta, etc.) and their relationship with the thyroid gland. No intraoperative uncontrolled bleeding was encountered. Hospital stay was calculated as an average of $5 \pm 3.2$ days (2-14). Post-operative hypocalcemia in $6(50 \%)$ patients and unilateral vocal cord paralysis in $1(8.3 \%)$ patient developed, and all complications resolved spontaneously within an average of 3 weeks. In 1(8.3\%) patient, hyperemia and cellulitis occurred on the incision, and they recovered with antibiotherapy and drainage (Fig. 5).

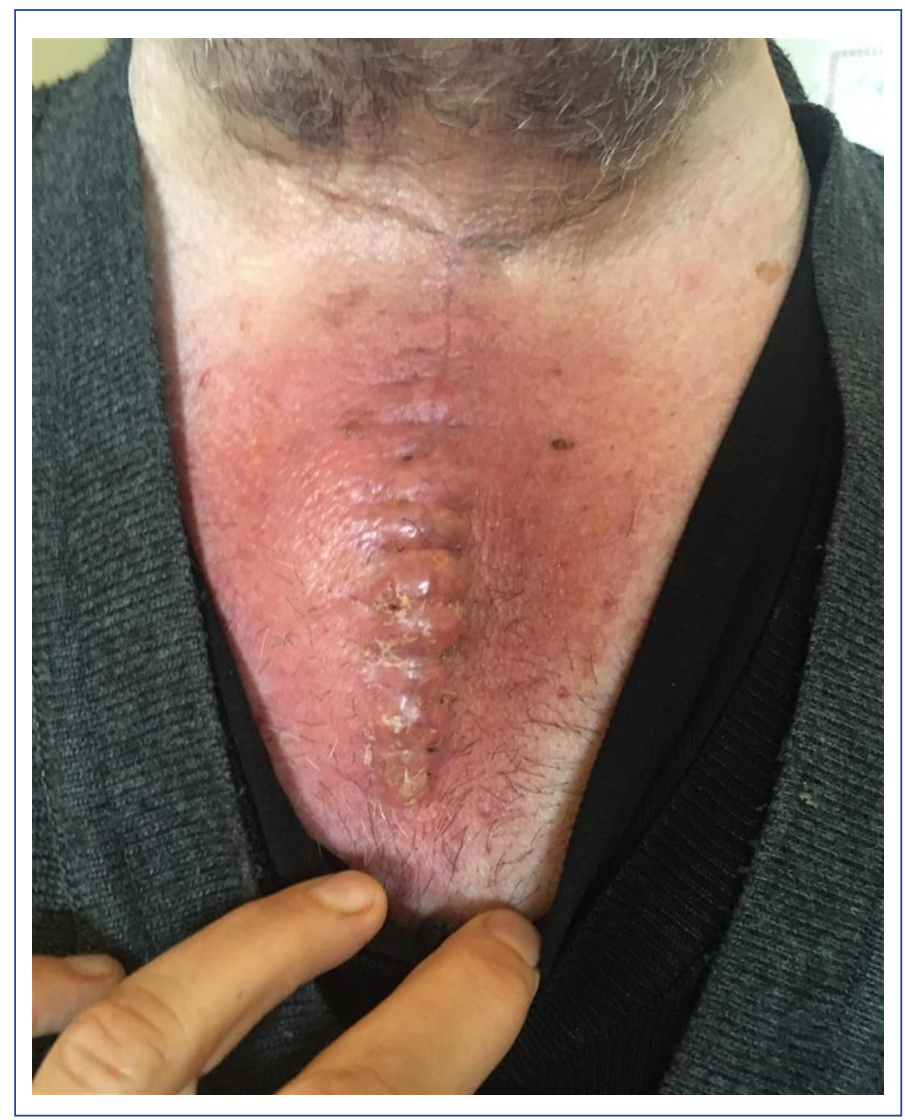

Figure 5. Patient with hyperemia and cellulitis in the incision. 
Table 1. Demographic and clinical characteristics of patients

\begin{tabular}{|c|c|c|}
\hline & $n=12$ & $\%$ \\
\hline \multicolumn{3}{|l|}{ Gender } \\
\hline Male & 4 & 33.3 \\
\hline Female & 8 & 66.7 \\
\hline \multicolumn{3}{|l|}{ Dyspnea } \\
\hline Yes & 7 & 58.3 \\
\hline No & 5 & 41.7 \\
\hline \multicolumn{3}{|l|}{ Extension to aortic arch } \\
\hline Yes & 5 & 41.7 \\
\hline No & 7 & 58.3 \\
\hline \multicolumn{3}{|l|}{ Mediastinal location } \\
\hline Anterior mediastinum & 11 & 91.7 \\
\hline Posterior mediastinum & 1 & 8.3 \\
\hline \multicolumn{3}{|l|}{ Previous cervical surgery } \\
\hline Yes & 6 & 50 \\
\hline No & 6 & 50 \\
\hline \multicolumn{3}{|l|}{ Surgical indication } \\
\hline MNG & 3 & 25 \\
\hline Recurrent MNG & 3 & 25 \\
\hline Primary HPT & 2 & 16.7 \\
\hline Secondary HPT & 1 & 8.3 \\
\hline Thyroid cancer & 3 & 25 \\
\hline \multicolumn{3}{|l|}{ Complication } \\
\hline Transient hypocalcemia & 6 & 50 \\
\hline Transient vocal cord paralysis & 1 & 8.3 \\
\hline Superficial surgical site infection & 1 & 8.3 \\
\hline No & 4 & 33.3 \\
\hline
\end{tabular}

MNG: Multinodular goiter; HPT: Hyperparathyroidism.

None of the patients had perioperative mortality or respiratory problems due to split sternotomy. Again, no patients required a median sternotomy (Table 1 ).

\section{Discussion}

As a generally accepted opinion, goiter that extends below the thoracic inlet or where more than half of the thyroid volume is below this level is defined as RG. ${ }^{[7]}$ Although several definitions have been proposed to be classified as RG, there is no consensus on the ratio of the gland in the substernal position to the whole gland or how deep the cervical goiter should extend in the thoracic cavity. ${ }^{[8]}$ The lack of a single accepted definition for RG has led to reports of very different RG incidence rates ranging from $0.2 \%$ to $45 \%$ in large thyroidectomy series. ${ }^{[7,9]} \mathrm{RG}$ may remain asymptomatic for many years or manifest with various symptoms due to compression on adjacent anatomical structures. About $20-40 \%$ of cases can be detected incidentally on radiological examination. ${ }^{[10]}$

The standard treatment method for symptomatic RG is surgery. Some of the asymptomatic RG patients can be followed up without surgical treatment. However, it has been reported that surgical intervention is required since follow-up and biopsy verification are not possible in the presence of a nodule. ${ }^{[11]}$ In addition, some authors ${ }^{[12]}$ recommend thyroidectomy for all RG cases since $72 \%$ of malignant foci were detected in the retrosternal part in malignant RG cases in their study and insufficient evaluation by ultrasonography on these cases. Total thyroidectomy is the optimal surgical approach to prevent RG recurrence, and total thyroidectomy with a cervical approach can be applied in more than $90-95 \%$ of the cases. ${ }^{[11]}$ In addition, it has been reported that early resection of RG will decrease the need for sternotomy in possible future surgery. ${ }^{[13]}$ Surgical intervention is recommended to be performed with a multidisciplinary approach and in high-volume centers experienced in endocrine surgery. ${ }^{[1]}$

RG surgery performed throughcervical approach or sternotomy/thoracotomy has higher complication rates than thyroidectomy performed througha cervical incision. ${ }^{[14]}$ There has been a dilemma regarding the usefulness of sternotomy in the surgery of RG with anterior mediastinal extension. While sternotomy facilitates dissection by widening the operative field of view, reduces the risk of recurrent nerve damage, and contributes to hemostasis in the event of injury to mediastinal thyroid vessels, it is considered as a procedure that increases morbidity due to post-operative incision-specific complications. ${ }^{[1,6]}$ Median sternotomy causes complications such as deep surgical site infections, sternal dehiscence, arrhythmias, sternal instability, and internal mammary vascular injuries, it has also been reported to prolong the duration of surgery and hospital stay. ${ }^{[15]}$

Considering that the majority of RGs can be safely resected with the cervical approach, an adequate pre-operative evaluation is necessary to identify patients who are likely to require a transsternal approach for safe thyroidectomy. ${ }^{\left[{ }^{[3]}\right.}$ Pre-operative neck and thorax CT contributes to the evaluation of the thyroid gland. With $\mathrm{CT}$, it is possible to determine the extension of the thyroid gland, its dimensions, its relationship with the main vascular structures, and the blood supply of the thyroid tissue from the mediastinal vascular structures other than the inferior thyroid artery. In a recently published study, mediastinal thyroid volume was measured with $\mathrm{CT}$, and it was reported that the mediastinal 
part of the thyroid's being more than $50 \%$ of the entire tissue and the mediastinal thyroid volume $\geq 162 \mathrm{~cm}^{3}$ were risk factors for an extracervical approach. ${ }^{[16]}$ In a recent review, extension below the aortic arch, goiter recurrence extending to the aortic arch, thyroid weight more than 260 $\mathrm{g}$, involvement of more than 1 mediastinal compartment, iceberg or conical morphology, extension to the posterior pleura, and goiter with separate components were found to be risk factors for thoracic approach. ${ }^{[1]}$

Ectopic inferior parathyroids located in the mediastinum are most commonly found in the anterior mediastinum, usually within the thymus gland, while ectopic superior parathyroids are usually found in the posterosuperior mediastinum. Less commonly, they can be found in the aortopulmonary window and rarely in the pericardium and the right dome of the diaphragm. ${ }^{[17]}$ In the past, a median sternotomy or thoracotomy was required for a mediastinal parathyroid adenoma. However, most of the cases can be resected with cervical thymectomy today. Still, in inaccessible lower located or large adenomas, mediastinal intervention may rarely be required to excise the gland without disturbing the integrity of the adenoma

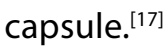

Minimally invasive techniques are being used in more and more centers for the diagnosis and treatment of mediastinal thyroid and parathyroid pathologies, depending on surgical experience and technical equipment. ${ }^{[1,18]}$ Split sternotomy, manubriotomy, mediastinoscopy, and VATS havefacilitated the surgical approach to the mediastinal thyroid and parathyroid gland thus reduced the need for total sternotomy. Since split sternotomy not extending to the internal mammary vessels, these vessels were preserved to use for possible future cardiac pathologies. Split sternotomy was performed instead of thoracoscopic intervention in one of the parathyroid adenomas located in the anterior mediastinum due to technical reasons and in others due to size.

This study has some limitations. Multicenter prospective studies involving more patients are needed to support our results due to limitations such as being conducted in a single clinic, retrospective data acquisition, and small sample size.

\section{Conclusion}

Mediastinal interventions in addition to cervical incision may be required in large, loweranterior retrosternal thyroid and anterior mediastinal located ectopic parathyroid pathologies. Split sternotomy is an adequate and feasible method that provides an adequate surgical field of view in these cases and has lower morbidity rates compared to total sternotomy.

\section{Disclosures}

Ethics Committee Approval: Ethics committee approval for this study was obtained from İzmir Katip Çelebi University Ethics Committee (decision number 1122, dated 24.12.2020).

Peer-review: Externally peer-reviewed.

Conflict of Interest: None declared.

Authorship Contributions: Concept - S.G.H., M.H.; Design - S.G.H., M.H.; Supervision - M.H.; Materials - M.H., B.E.; Data collection \&/or processing - S.H., S.K., N.A.; Analysis and/or interpretation - S.H., S.K., N.A.; Literature search - S.H., S.K., N.A.; Writing - S.H., S.K.; Critical review - M.H.

\section{References}

1. Hanson MA, Shaha AR, Wu JX. Surgical approach to the substernal goiter. Best Pract Res Clin Endocrinol Metab 2019;33:101312. [CrossRef]

2. Coskun A, Yildirim M, Erkan N. Substernal goiter: when is a sternotomy required? Int Surg 2014;99:419-25. [CrossRef]

3. Marcelino M, Nobre E, Conceição J, Lopes L, Vilar H, de Castro $J J$. Superior vena cava syndrome and substernal goiter. Thyroid 2010;20:235-6. [CrossRef]

4. Mercante G, Gabrielli E, Pedroni C, Formisano D, Bertolini L, Nicoli $F$, et al. CT cross-sectional imaging classification system for substernal goiter based on risk factors for an extracervical surgical approach. Head Neck 2011;33:792-9. [CrossRef]

5. Alesina PF, Moka D, Mahlstedt J, Walz MK. Thoracoscopic removal of mediastinal hyperfunctioning parathyroid glands: personal experience and review of the literature. World J Surg 2008;32:224-31. [CrossRef]

6. Pata G, Casella C, Benvenuti M, Crea N, Di Betta E, Salerni B.'Ad hoc' sternal-split safely replaces full sternotomy for thyroidectomy requiring thoracic access. Am Surg 2010;76:1240-3. [CrossRef]

7. White ML, Doherty GM, Gauger PG. Evidence-based surgical management of substernal goiter. World J Surg 2008;32:1285-300. [CrossRef]

8. Simó R, Nixon IJ, Vander Poorten V, Quer M, Shaha AR, Sanabria $A$, et al. Surgical management of intrathoracic goitres. Eur Arch Otorhinolaryngol 2019;276:305-14. [CrossRef]

9. Raffaelli $M$, De Crea $C$, Ronti S, Bellantone R, Lombardi CP. Substernal goiters: incidence, surgical approach, and complications in a tertiary care referral center. Head Neck 2011;33:1420-5. [CrossRef]

10. Erbil Y, Bozbora A, Barbaros U, Ozarmağan S, Azezli A, Molvalilar $S$. Surgical management of substernal goiters: clinical experience of 170 cases. Surg Today 2004;34:732-6. [CrossRef]

11. Yoldas T, Makay O, Icoz G, Kose T, Gezer G, Kismali E, et al. Should subtotal thyroidectomy be abandoned in multinodular 
goiter patients from endemic regions requiring surgery? Int Surg 2015;100:9-14. [CrossRef]

12. Sahbaz NA, Tutal F, Aksakal N, Acar S, Aksu Kl, Barbaros $\mathrm{U}$, et al. Cancer frequency in retrosternal goiter. Am Surg 2017;83:1390-3. [CrossRef]

13. Doulaptsi M, Karatzanis A, Prokopakis E, Velegrakis S, Loutsidi A, Trachalaki $A$, et al. Substernal goiter: Treatment and challenges. Twenty-two years of experience in diagnosis and management of substernal goiters. Auris Nasus Larynx 2019;46:246-51. [CrossRef]

14. Moten AS, Thibault DP, Willis AW, Willis AI. Demographics, disparities, and outcomes in substernal goiters in the United States. Am J Surg 2016;211:703-9. [CrossRef]

15. Testini M, Gurrado A, Avenia N, Bellantone R, Biondi A, Brazzarola $P$, et al. Does mediastinal extension of the goiter increase morbidity of total thyroidectomy? A multicenter study of 19,662 patients. Ann Surg Oncol 2011;18:2251-9. [CrossRef]

16. Sormaz iC, Uymaz DS, İşcan AY, Özgür İ, Salmaslıoğlu A, Tunca $F$, et al. The value of preoperative volumetric analysis by computerised tomography of retrosternal goiter to predict the need for an extra-cervical approach. Balkan Med J 2018;35:36-42. [CrossRef]

17. Hu J, Ngiam KY, Parameswaran R. Mediastinal parathyroid adenomas and their surgical implications. Ann R Coll Surg Engl 2015;97:259-61. [CrossRef]

18. Siddiqi MS, Al Badai Y, Al Kemyani NA, Al Kindi AH. Combined transcervical and thoracoscopic mediastinal parathyroid adenoma resection. Asian Cardiovasc Thorac Ann 2016;24:593-6. [CrossRef] 